\title{
Infrared thermography study of the fatigue crack propagation
}

\author{
A.Yu. Fedorova, M.V. Bannikov, O.A. Plekhov \\ Institute of Continuous Media Mechanics UB RAS,614013, Ac. Koroleva Street, 1, Perm, Russia \\ E.V. Plekhova \\ Perm National Research Polytechnic University,614990, Komsomolsky av, 29, Perm, Russia
}

\begin{abstract}
The work is devoted to the experimental study of heat dissipation process caused by fatigue crack propagation. To investigate a spatial and time temperature evolution at the crack tip set of experiments was carried out using specimens with pre-grown centered fatigue crack. An original mathematical algorithm for experimental data treatment was developed to obtain a power of heat source caused by plastic deformation at crack tip. The algorithm includes spatial-time filtration and relative motion compensation procedures. Based on the results of mathematical data treatment, we proposed a way to estimate the values of J-integral and stress intensity factor for cracks with pronounced the plastic zone.
\end{abstract}

KEYWORDS. Fatigue crack; Heat dissipation; Infrared thermography.

\section{INTRODUCTION}

I $\mathrm{n}$ recent decades, many authors have been actively investigated the processes of heat dissipation due to the material structure evolution under cyclic loading. The main application of infrared thermography for fatigue loading was focused on the development of techniques for rapid determination of fatigue limit of materials. This technique was reported starting from early work by A. Risitano [1], developed further by M.P. Luong [2] and many other authors. The review of this question can be read in [3].

But there are only a few works devoted to direct investigation of temperature evolution at fatigue crack tip. At present, it is well known that in materials under cyclic deformation, fatigue cracks are initiated in the area of plastic deformation localization and lead to an intensive heat dissipation [4]. It makes possible the early detection of crack initiation by infrared thermography [5]. The infrared thermography can be also applied during mechanical tests in order to obtain detailed information about the process of structure evolution, damage accumulation and damage-fracture transition in solids [6-8]. The investigation of the heat dissipation at the fatigue crack tip allows one to develop an effective method for determination of the linear fracture mechanics parameters in a wide range of stress intensity and, as a consequence, gives a way of monitoring of critical state of crack. The solution of this problem requests an analysis of solutions of nonlinear problems of plasticity theory and experimental investigation of plastic deformation localization at crack tip.

This work is devoted to the development of experimental technique for measuring the temperature field at the crack tip with a high temperature and spatial resolution. The technique is coupled with mathematical algorithms for experimental data processing. The algorithms allow us to determine the stress intensity factor (SIF) and propose an idea for calculation of J-integral value as a value of energy dissipated at crack tip. The proposed algorithms are universal and can be used for many metals under cyclic loading with different stress amplitudes and frequencies. In this work we applied this technique for study of temperature evolution of the plate titanium specimens with pre-grown fatigue crack. We experimentally investigated the evolution of the temperature distribution and obtained the values of heat dissipation caused by plastic deformation at the fatigue crack. 


\section{MATERIALS AND CONDITIONS OF EXPERIMENT}

$\mathrm{E}$ xperimental study of temperature evolution at the fatigue crack tip was carried out on the plane specimens of titanium Ti-6Al-4V. The specimens were manufactured from a commercial pure titanium sheet $3 \mathrm{~mm}$ thick. The chemical composition of material presented in Tab. 1.

\begin{tabular}{cccccccccc}
\hline $\mathrm{Fe}$ & $\mathrm{C}$ & $\mathrm{Si}$ & $\mathrm{V}$ & $\mathrm{N}$ & $\mathrm{Ti}$ & $\mathrm{Al}$ & $\mathrm{Zr}$ & $\mathrm{O}$ & $\mathrm{H}$ \\
0.3 & 0.1 & 0.15 & 4.2 & 0.03 & other & 5.9 & 0.2 & 0.2 & 0.015 \\
\hline
\end{tabular}

Table 1: Chemical composition of Ti-6Al-4V.

Mechanical properties of material are modulus of elasticity - $113 \mathrm{GPa}$, yield stress - $800 \mathrm{MPa}$, ultimate stress $900 \mathrm{MPa}$, fatigue limit - $460 \mathrm{MPa}$, fracture toughness $-75.6 \mathrm{MPa} \sqrt{\mathrm{m}}_{\text {. }}$

The geometry of specimen is shown in Fig. 1. The specimens were weakened by holes to initiate fatigue crack at the specimen center. The fatigue crack (about $10 \mathrm{~mm}$ ) was initiated at the initial stage of the experiment by high amplitude cyclic loading of the specimens at the average stress of $215 \mathrm{MPa}$, stress amplitude of $238 \mathrm{MPa}$ and loading frequency of 20 Hz. Then the load was decreased to slow down the rate of crack propagation, which allows a detailed analysis of the heat generation processes at the crack tip.

The surface of the specimens was polished in several stages by the abrasive paper (at the final stage of polishing the grit size does not exceed $3 \mu \mathrm{m}$ ). Before starting the experiment, the polished surface was covered by a thin layer of amorphous carbon.

The temperature evolution was recorded by infrared camera CEDIP Silver 450M. The spectral range of the camera is 3-5 $\mathrm{mm}$. The maximum frame size is $320 \times 256$ pixels; the spatial resolution is $10-4$ meters. The temperature sensitivity is 25 $\mathrm{mK}$ at $300 \mathrm{~K}$. Calibration of the camera was made based on the standard calibration table.

Mechanical tests were carried out at $100 \mathrm{kN}$ servo-hydraulic machine Bi-00-100. The test conditions comply with the conditions of the experiment was described in [9]. The process of crack propagation was studied at $5 \mathrm{~Hz}$ and $10 \mathrm{~Hz}$ loading frequency.

The selected frequency of loading provides a close to adiabatically condition at crack tip. At low frequency (less that $5 \mathrm{~Hz}$ ) the heat transfer process plays a great role and doesn't allow one to calculate the right value of heat source. The investigation of high loading frequency requests the high frame rate and treatment of large amount of infrared data. It was shown that for selected values of loading frequency the value of determined parameters (stress intensity factor) depends on the applied stress and crack length, only.

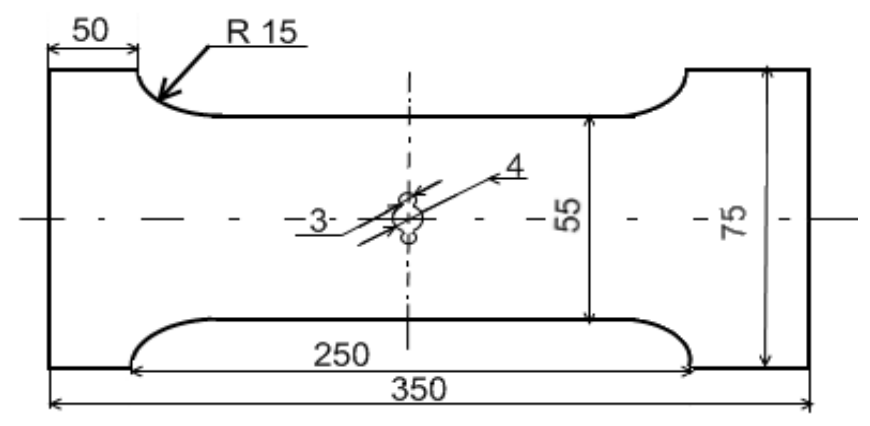

Figure 1: Geometry of specimen. All sizes are in millimeters.

\section{THE PROCESSING OF THE EXPERIMENTAL DATA}

A $\mathrm{t}$ the beginning of data processing procedure, the first frame was subtracted from the film to eliminate the influence of infrared radiation from the camera lens on the determined temperature field.

Due to the relative motion of the specimen and infrared camera lens under cyclic tests, there is the problem of motion compensation in order to obtain the correct temperature data at a given point on specimen surface. Compensation of relative motion was made based on the following algorithm. 
Using the discrete Fourier transform we can processed all frames of the film

$$
T_{t}\left(k_{x}, k_{y}\right)=\int_{-\infty}^{\infty} \int_{-\infty}^{\infty} \exp \left(-i\left(k_{x} x+k_{y} y\right)\right) T_{t}(x, y) d y d x,
$$

where

$x, y$ - spatial coordinates,

$t$ - number of frame,

$T_{t}(x, y)$ - temperature at $\mathrm{t}$-th infrared frame,

$\mathrm{i}=\sqrt{-1}$.

To find the relative motion value we used arbitrary selected fragment of first frame of the film ("flag"). One of the variants of "flag" is presented in Fig. 2.

Using the Fourier image of first frame

$$
T_{1}\left(k_{x}, k_{y}\right)=\int_{-\infty}^{\infty} \int_{-\infty}^{\infty} \exp \left(-i\left(k_{x} x+k_{y} y\right)\right) T_{1}(x, y) d y d x,
$$

we can define the position of the chosen fragment in the subsequent frames of the film as follows

$$
T_{t}(x, y)=\int \frac{1}{(2 \pi)^{2}} \exp \left(-i\left(k_{x} x+k_{y} y\right)\right) T_{t}\left(k_{x}, k_{y}\right) T_{1}\left(k_{x}, k_{y}\right) d k_{x} d k_{y},
$$

The dependence of the "flag" coordinates versus time determines the absolute value of the displacement of each pixel in the image and allows us to compensate for the relative motion.

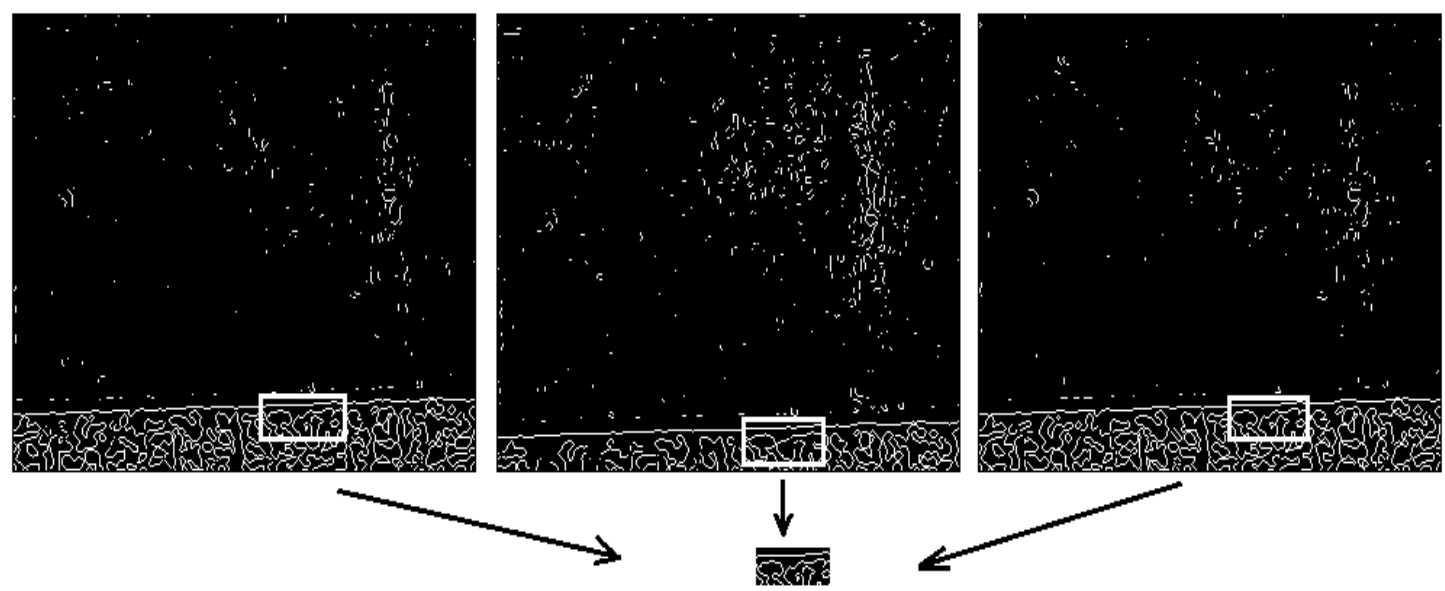

Figure 2: Implementation of the motion compensation algorithm for the temperature contour images.

Spatially fixed temperature signal of the specimen was processed by the two-dimensional discrete Fourier transform with the standard Gaussian kernel to increase data accuracy and eliminate the influence of random temperature fluctuations. The expression for determining the temperature had the form

$$
T(x, y)=\int \frac{1}{(2 \pi)^{2}} \exp \left(-i\left(k_{x} x+k_{y} y\right)\right) \widehat{T}\left(k_{x}, k_{y}\right) \widehat{f}\left(k_{x}, k_{y}\right) d k_{x} d k_{y},
$$

where

$f(x, y)=\frac{v^{2}}{\pi} \exp \left(-v^{2}\left(x^{2}+y^{2}\right)\right)-$ Gaussian kernel,

$\hat{f}\left(k_{x}, k_{y}\right)$ - direct Fourier transform of the standard Gaussian kernel, 
$\widehat{T}\left(k_{x}, k_{y}\right)$ - direct Fourier transform of the temperature.

The initial temperature distribution and temperature distribution obtained using equation (4) are shown in Fig. 3.

Finally, an infrared image of the temperature increment on the specimen surface during crack propagation is shown in Fig. 4 after all stages of signal processing.

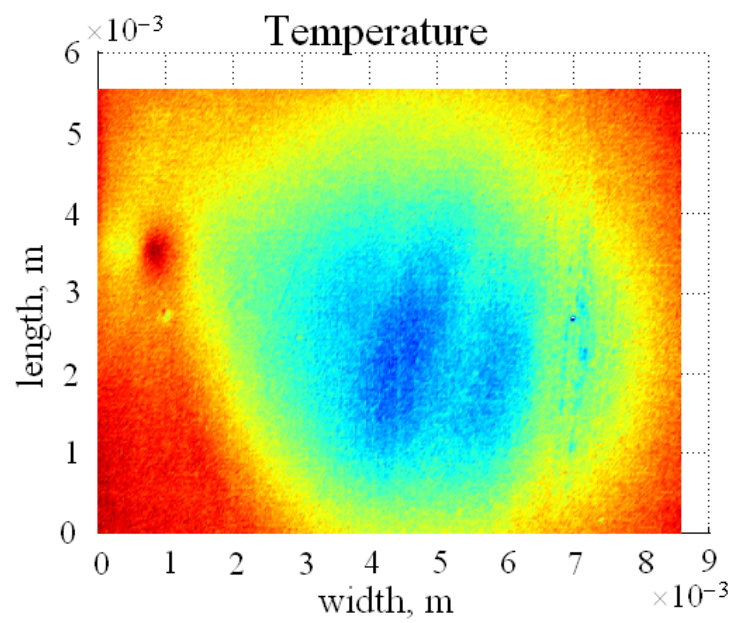

a)

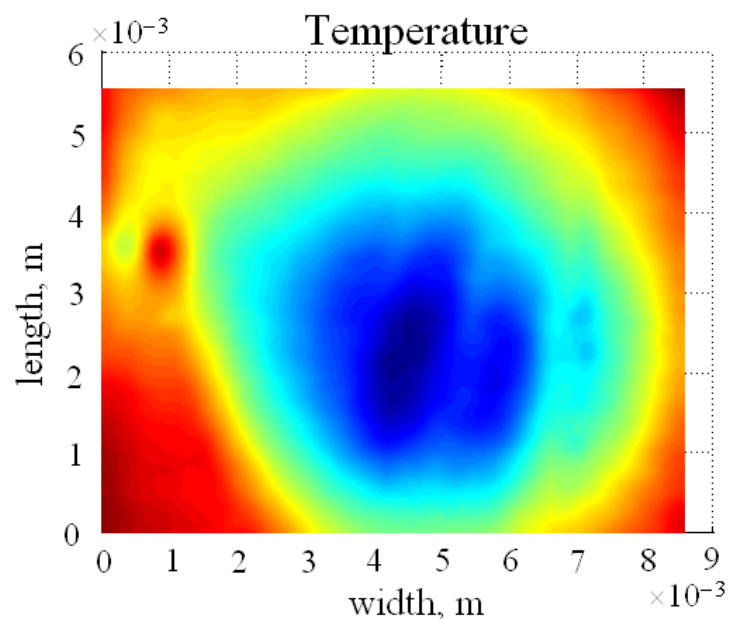

b)

Figure 3: The temperature field before (a) and after (b) data processing.

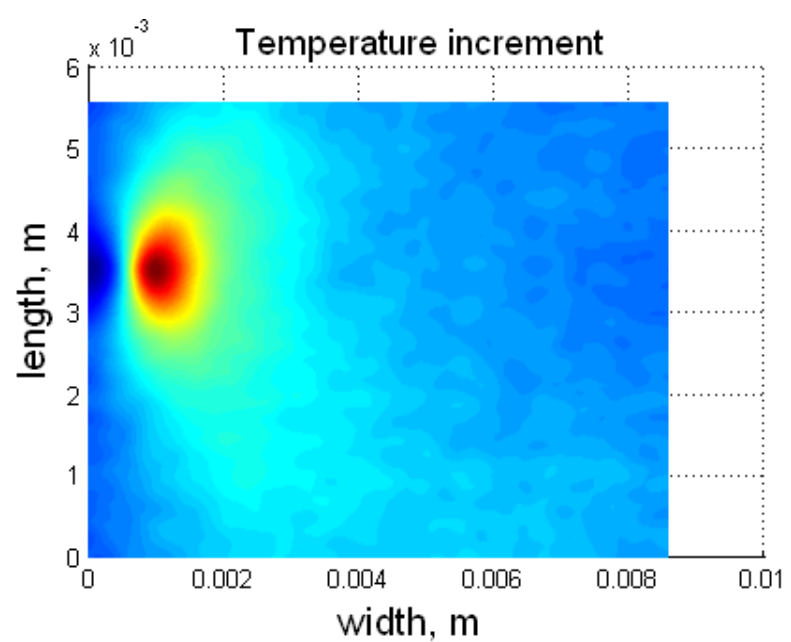

Figure 4: The temperature field after all stages of signal processing.

\section{DETERMINATION OF THE HEAT DISSIPATED AT THE CRACK TIP CAUSED BY PLASTIC DEFORMATION}

$\mathrm{T}$ he value of the specific heat power at the crack tip can be determined using the following relation [10]

$s=\rho c\left(\dot{T}+\frac{T}{\tau}\right)-k \Delta T$,

where

$T$ - temperature,

$\varrho$ - density $\left(4505 \mathrm{~kg} / \mathrm{m}^{3}\right)$,

$c$ - heat capacity $(540 \mathrm{~J} /(\mathrm{kg} \cdot \mathrm{K}))$,

$k$ - heat conductivity $(18.85 \mathrm{~W} /(\mathrm{m} \cdot \mathrm{K}))$, 
$s-$ unknown specific power of the heat source $\left(\mathrm{W} / \mathrm{m}^{3}\right)$,

$\tau-$ a constant related to the losses of heat by heat exchange with the surroundings $\left(10^{3} \mathrm{~J} /\left(\mathrm{m}^{3} \cdot \mathrm{K}\right)\right)$.

The resulting value of the specific power of heat source was integrated over the time during which the plastic zone was observed. The profile of the specific heat dissipated during plastic deformation is plotted in Fig. 5.

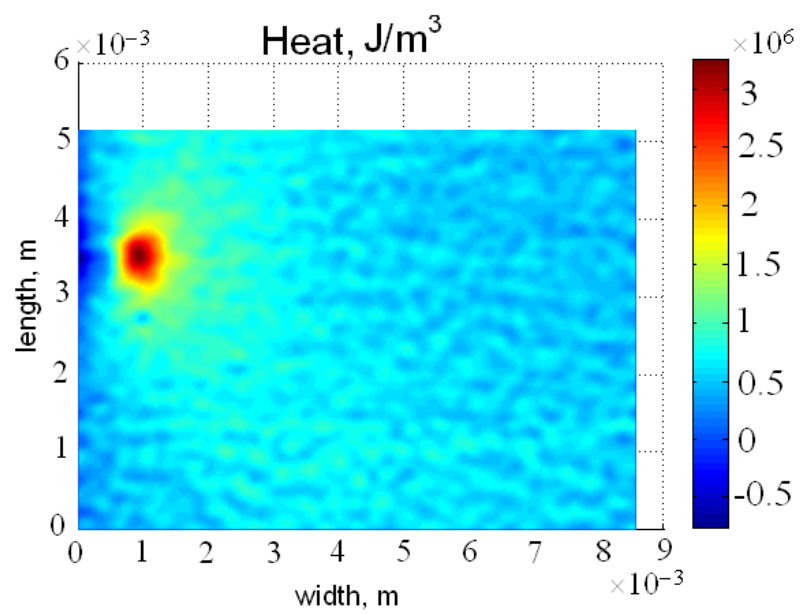

a)

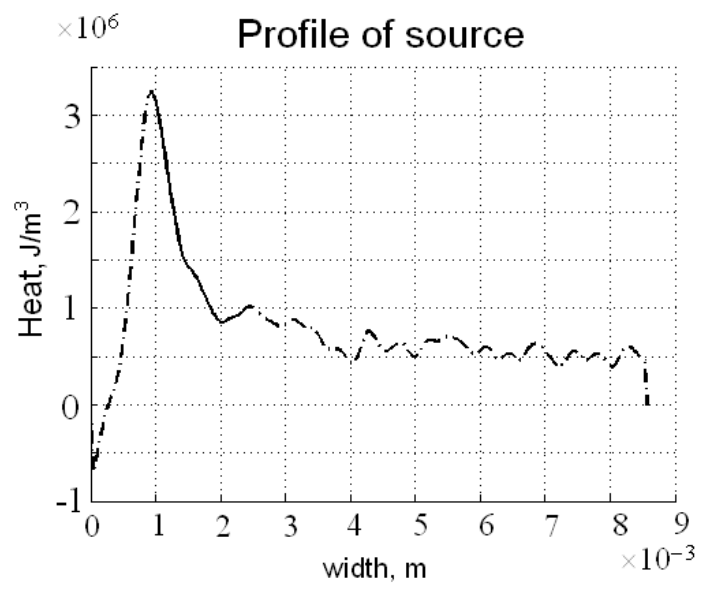

b)

Figure 5: Specific heat $\left(\mathrm{J} / \mathrm{m}^{3}\right)$ dissipated during plastic deformation (a) and its profile in the direction of crack propagation (b).

The developed algorithm allows us to study a time evolution of temperature evolution and heat dissipation processes at the crack tip. The plots of the temperature increment, heat and stress of two types of experiments are presented in Fig. 6. At the beginning of cycling, the thermoelastic effect leads to emergence of cooling zone at crack tip, the local transition through the yields stress leads to temperature increase caused by the formation of a plastic deformation zone. When the stress decreases, the heat dissipation at the crack tip continues the heat dissipation rises and the temperature reaches a maximum at the falling load. At the beginning of the next cycle, the temperature again decreases due to the thermoelastic effect and the process repeats.

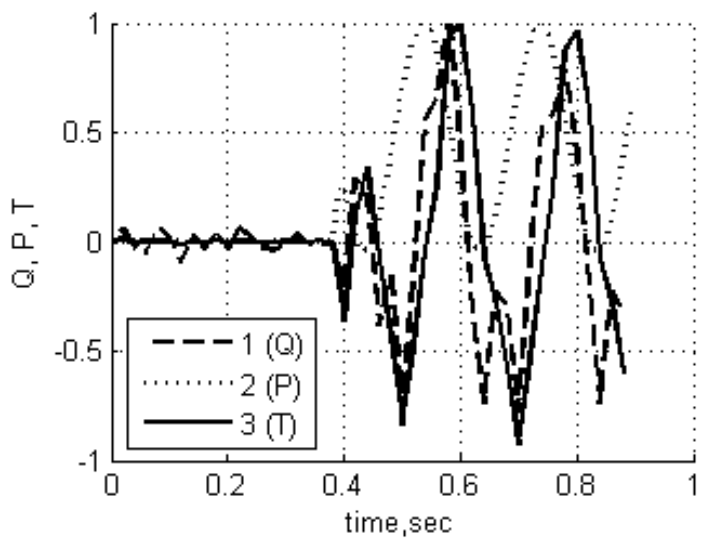

a)

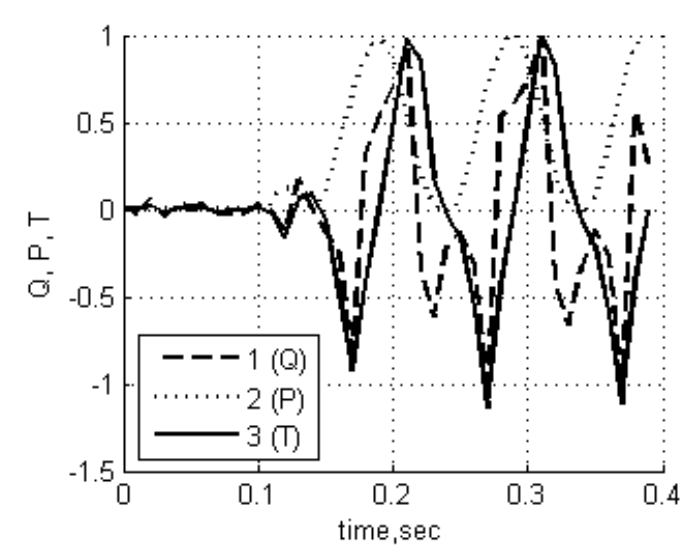

b)

Figure 6: Heat source evolution (1), loads (2) and the temperature increment (3) at the crack tip during the loading. Loading frequency is $5 \mathrm{~Hz}$ (a), loading frequency - $10 \mathrm{~Hz}(\mathrm{~b})$.

The Fig. 7 presents the detail analysis of the temperature evolution near fatigue crack tip in the direction of the crack propagation. The legends indicate the time of temperature distribution. The data corresponds to the test presented with stress amplitude $250 \mathrm{MPa}$ and frequency $10 \mathrm{~Hz}$. 
Analysis of the data presented in Fig. 6, 7 allows us to suggest that the maximum of applied loads and the maximum of heat dissipation intensity in the fatigue crack tip do not coincide in time. The observed effect shows that there is a lag of temperature reaction of the specimen on the changing loading during the cyclic deformation.

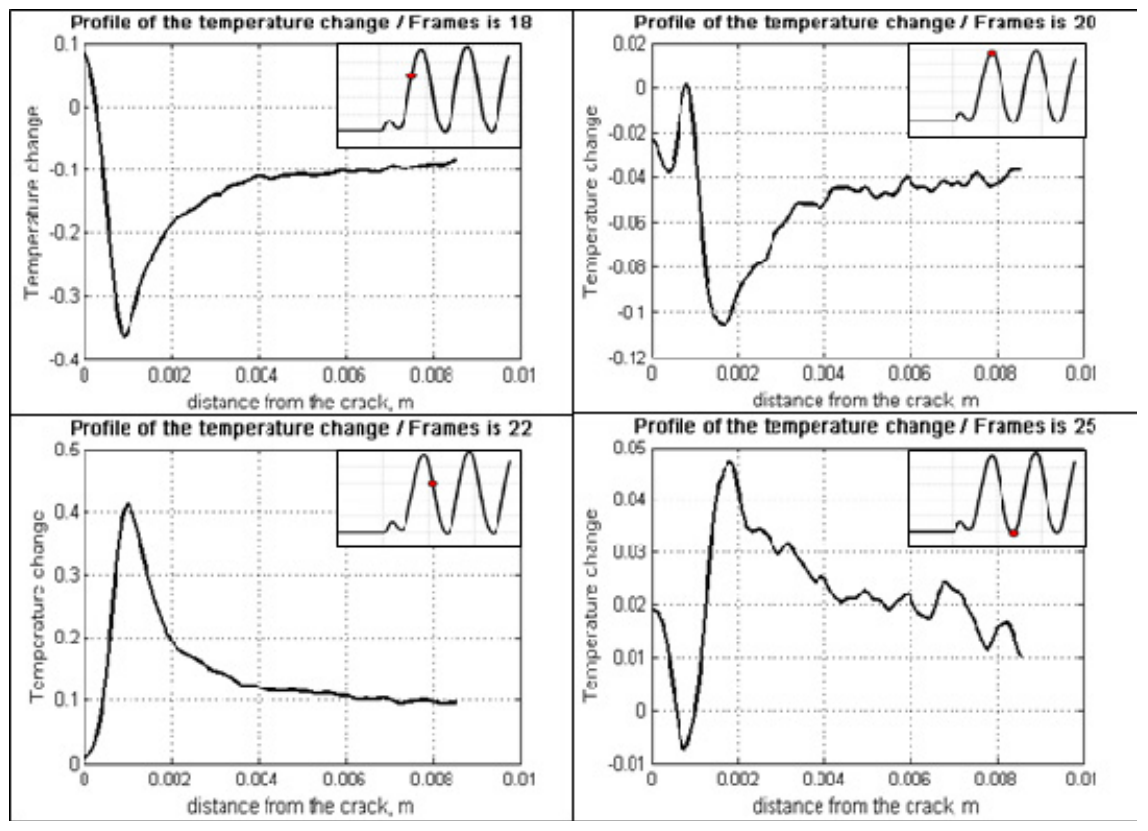

Figure 7: Evolution of temperature distribution in the direction of crack propagation versus applied stress.

The obtained data of the heat dissipation rate at the crack tip allows us to propose an idea to determining the values of Jintegral as a value of energy dissipated at crack tip. Based on it we can calculate the SIF and offer in a criterion for the critical state of the material, based on the experimentally observed size of the plastic deformation zone.

Using the HRR-solution [11], we can expect that the energy released at the crack tip $\left(\mathrm{W}_{\mathrm{p}}\right)$ has a singularity $1 / \mathrm{r}$ and is proportional to the value of the J-integral

$$
W_{p}=m_{1} \frac{J(x)}{r},
$$

where

$r$ - distance from the crack tip,

$m_{1}-$ coefficient associated with the properties of the sample material and the type of loading,

$J(x)$ - J-integral.

For the sake of simplicity, we assume that the energy released at the crack tip is consumed to the heat dissipation. Then, based on experimental evidence, we can calculate the value of J-integral and SIF according to the formulas

$$
\begin{aligned}
& J(x)=\frac{Q(x) r}{m_{1}}, \\
& K=\sqrt{\frac{E J(x)}{1-v^{2}}}
\end{aligned}
$$

where

$\nu=0.32-$ Poisson's coefficient,

$E$ - Young's modulus,

$Q(x)$ - specific heat $\left(\mathrm{J} / \mathrm{m}^{3}\right)$.

To check the accuracy of experimentally calculate values of SIF we calculate the theoretical value of SIF as follow

$$
K_{\text {Theor }}=P \sqrt{\pi l \sec \left(\frac{\alpha \pi}{2}\right)},
$$


where

$P$ - tensile force $(\mathrm{Pa})$,

$l$ - half-length of crack,

$\alpha=2 l / h$,

$b$ - width of the sample.

The values of J-integrals and SIF were calculated based on the formulas (7) - (9). The results are shown in Fig. 8 and Fig. 9

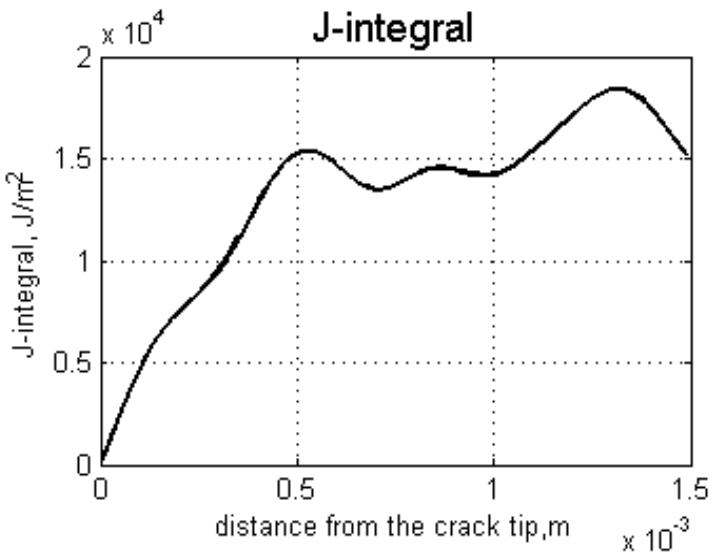

a)

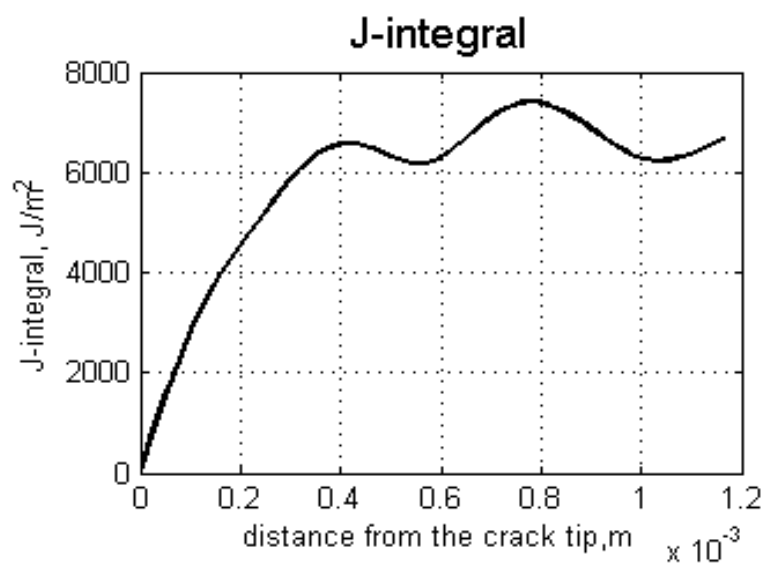

b)

Figure 8: The dependence of J-integral versus a distance from the crack tip in the direction of crack propagation. Loading frequency is $5 \mathrm{~Hz}$ (a), loading frequency $-10 \mathrm{~Hz}(\mathrm{~b})$.

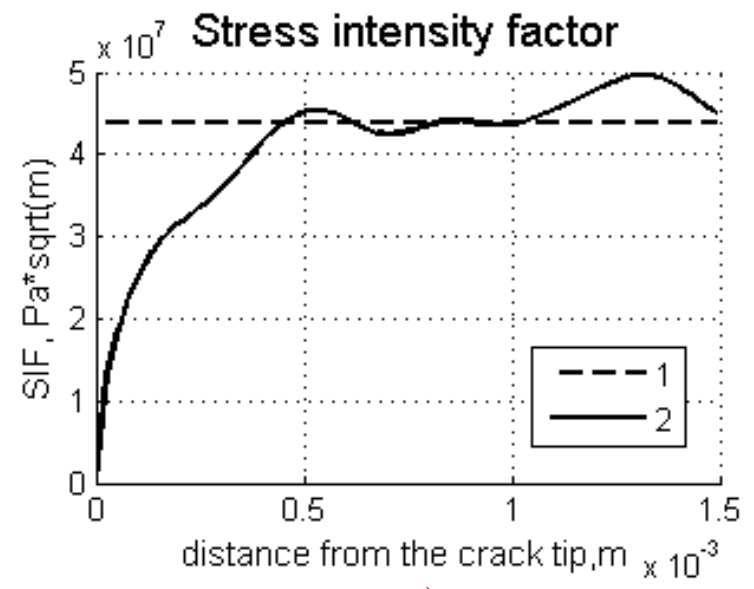

a)

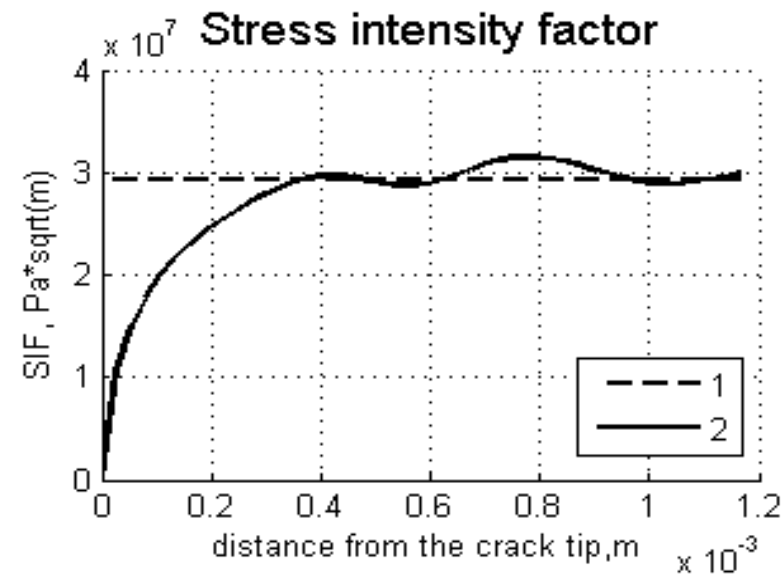

b)

Figure 9: The dependence of SIF versus a distance from the crack tip in the direction of crack propagation. Loading frequency is $5 \mathrm{~Hz}$ (a), loading frequency - $10 \mathrm{~Hz}(\mathrm{~b})$.

Analysis of the data presented in Fig. (8), (9) suggests that the average value of experimentally obtained SIF is approximately equal to the theoretical value of SIF at a distance from $0.4 \mathrm{~mm}$ to $1.2 \mathrm{~mm}$ from the crack tip. This allows us to use the equations (7-9) to determine the critical condition of the crack with pronounced plastic deformation zone.

\section{CONCLUSION}

he effect of heat dissipation at the crack tip under cyclic loading has been studied based on the infrared thermography. To calculate the values of heat dissipation at crack tip an original data processing algorithms were developed. The algorithms include the relative motion compensation and spatial-time filtration procedures. As a 
result of infrared data treatment we determine the key characteristics associated with the heat dissipation processes at the crack tip, which allowed us to propose method for determining the current values of the J-integral and SIF.

The sphere of applicability of this technique is wider than previously proposed methods for determining the SIF based on the linear thermo-elasticity equations. The set of developed mathematical algorithms and methods of the experiment significantly increases the accuracy of the results compared with previously published studies [9], and allows us to develop in a future an engineering methods for analyzing the current crack state inside of real constructions in a wide range of applied loads.

\section{REFERENCES}

[1] A Geraci, G. La Rosa, A. Risitano, In: CRES Symposium, Catania Italy, (1984); published in: ATA Ingegneria Automotoristica, 38(8-9) (1985).

[2] M.P. Luong, Mech. Mater.,28 (1988) 155.

[3] A. Risitano, G. Risitano, Theoretical and Applied Fracture Mechanics, 54 (2010) 82.

[4] A. A. Shanyavskiy, Bezopasnoe ustalostnoe razrushenie elementov aviakonstrukcii. Sinergetika v ingenernih prilogeniyah [Safe fatigue damage of aircraft construction elements. Synergetics in engineering applications]. Ufa, (2003) 803

[5] V. P. Vavilov, Diagnostika materialov, 72(3) (2006) 26.

[6] M.P. Luong, Nuclear Engineering and Design., 158 (1995) 363.

[7] O. Plekhov, T. Palin-Luc, O. Naimark, S. Uvarov, N. Saintier, Fatigue and fracture of engineering materials and structures, 28(1) (2005) 169.

[8] O. Plekhov, N. Saintier, T. Palin-Luc, S. Uvarov, O. Naimark, Material Science and Engineering A, 462(1) (2007) 367.

[9] M. Bannikov, A. Terekhina, O. Plekhov, Vestnik Permskogo gosudarstvennogo tehnicheskogo universiteta. Mehanika, 2 (2011) 14.

[10] O. Plekhov, Technical Physics, 56(2) (2011) 301.

[11] Nagahisa Ogasawara, Masaki Shiratori, Application of infrared thermography to fracture mechanics, SPIE Digital Library, 3056 (0277-786X/97), available at: http://spiedl.org/terms. 